\title{
Local experience, knowledge, and community adaptations to environmental change: the case of a fishing village in central Vietnam
}

\author{
Henner Leithäuser ${ }^{1}$ (D) $\cdot$ Ronald Lindsey Holzhacker ${ }^{1}$ \\ Received: 21 January 2020 / Accepted: 2 September 2020 / Published online: 21 September 2020 \\ (C) The Author(s) 2020
}

\begin{abstract}
Local ecological knowledge (LEK) represents an important link between resource users and their social-ecological system and plays a key role regarding the sustainable planning of environmental resources. This study investigates the nature of LEK in the case of a fishing village at the Tam Giang Lagoon in central Vietnam by applying an ethnographic participant observer approach. The research demonstrates a means to understand a complex, self-organized local network with a multitude of actors with different interests and adaptive behaviors, interfering in diverse and sometimes contradictory ways in the same environmental context. It concludes with two understandings about LEK. (1) It is important to recognize it as a concept that is not fixed in time and space as it is coevolving with broader system changes. (2) Only if approached through careful immersion and participation at the local level can it provide a valuable source of science-based information for improved decision-making.
\end{abstract}

Keywords Local ecological knowledge $\cdot$ Adaptive planning $\cdot$ Knowledge sharing $\cdot$ Ethnography $\cdot$ Vietnam $\cdot$ Southeast Asia

\section{Introduction}

There are many small fishing and agricultural villages at the edge of rapidly developing cities in the least developed countries (LDCs) and middle-income countries (MICs), which face a variety of social and environmental challenges. Coastal ecosystems and their resources on which these villages depend are rapidly degrading due to industrial activity and a range of other anthropogenic drivers of change, while their social structure is undergoing changes due to the attractiveness and growing income opportunities of nearby cities. Local ecological knowledge (LEK) plays a key role for the scientists and planners of environmental resources involved in the sustainable development of these regions (Agrawal 1995; Al-Roubaie 2010; Bohensky and Maru 2011; Whyte 2013). This importance, however, has only recently begun to receive formal recognition (Mamun 2010; McGregor 2014) and there is still

Communicated by Tony Weir

Henner Leithäuser

henner.leithauser@gmail.com

1 Faculty of Spatial Sciences, University of Groningen, Groningen, The Netherlands much uncertainty regarding how this specific way of knowing should be translated into broadly accepted scientific paradigms (Agrawal 1995; Houde 2007; Whyte 2013; Rathwell et al. 2015). Whyte (2013) pointed out that instead of debating the general definition and scientific applicability of LEK, scientists should regard it as a collaborative concept and thus focus on bidirectional knowledge transfer (see also Fazey et al. 2012). A growing number of studies show various existing barriers regarding the integration of LEK into conventional management and policymaking processes, with one major challenge being the reluctance of officials to acknowledge LEK as a relevant and scientifically valid form of advice (Ross et al. 2011; Abelshausen et al. 2015; Benham 2017; Berkes 2017; Phuong et al. 2018). Local stakeholders, on the other hand, are often more open to change and are willing to be educated by science (Abelshausen et al. 2015; Nguyen and Ross 2017). However, bidirectional exchange inherently means that not only locals need to be able to participate in planning processes, but planners also need to participate in local processes. For this, there is a need to develop more formal mechanisms (Fazey et al. 2012; Nguyen and Ross 2017).

In this case study, applying the scientific method of ethnographic participant observation (Hammersley and Atkinson 2007), we captured local experiences with social-ecological 
change in a rural village on the northern banks of the Tam Giang Lagoon in central Vietnam and the resulting adaptations from these experiences within the village network. Subsequently, in the later parts, we aim to show that in this way a planner is enabled to review and grasp the understanding and representation that the inhabitants have of their particular environmental situation. The research question is as follows:

How may a review of the concept of local ecological knowledge (LEK), applied through the lens of an ethnographic participant observer approach, enhance the planning of local environmental resources?

Being able to access the vast repertoire of locally constituted knowledge can provide valuable insights from different perspectives and otherwise not yet codified or contextualized narratives (Bennett et al. 2015). With our focus on a particular village in Vietnam, we wish to provide a carefully considered empirical example of the opportunities, but also challenges of using LEK, in a non-democratic, rapidly developing, and industrializing country in a traditional agricultural and fishingbased setting in Southeast Asia. Officials in conventional science-dominated environmental planning in Vietnam often have taken little consideration of LEK; however, there have been efforts at the co-planning of natural resources (Van Tuyen 2006; Van Tuyen et al. 2010) along with the rise of adaptive management methods in science over the past two decades (Nadasdy 2007). The case of the small fishing village of Trung Làng was selected, since the location has already been a site of such co-planning trials. There were hopes in the area to avert a possible collapse of the invaluable hotspot of biodiversity and natural resources, following decades-long uncontrolled economic exploitation (Abelshausen et al. 2015). The area has been subjected to environmental degradation over the past decades, including changes related to climate change and pollution. Locals have grown accustomed to the presence of scientists and government planning officials studying the situation, and thus residents are generally open to participation with outsiders and sharing their experiences with a researcher.

\section{Methods}

Following Whyte (2013), an endeavor to approach LEK inevitably leads to collaborative engagement. Thus, any scientific research approach should facilitate true bidirectional knowledge transfer between scientists and LEK owners who are impacted by environmental change and planning issues through close contact and embeddedness. The approach needs to provide the flexibility to embrace LEK as a fluid concept that often also imbeds aspects which are not easily expressed in scientific terms (Agrawal 1995; Berkes 2017) yet is still also founded in scientific practice to be respected by western-trained decision-makers (Stevenson 2006; Houde 2007; Ross et al. 2011).

The ethnographic participant observer approach, which is, similar to LEK, strongly rooted in natural experimentation and local empiricism (Agrawal 1995; Ehlert 2014) has the potential to fulfill these requirements. Hammersely and Atkinson define the approach as:

The embeddedness and participation in people's daily lives for an extended period of time, watching what happens, listening to what is said, and asking questions through informal and formal interviews, collecting documents, artifacts [and photographs] - in fact, gathering whatever data are available to throw light on the issues that are the emerging focus of inquiry. (Hammersely and Atkinson 2007: 3)

Specifically for the case of Vietnam, this approach provides the freedom of movement within the context of the rigidly formalized research culture and flexibility regarding site selection and continuous engagement in trust building and participation in daily activities over longer periods (Ehlert 2014). In return, it requires researchers to critically reflect on their own perceptions to identify possible bridges and cross-scale institutional links between different knowledge systems of formal adaptive planners and grassroots actors, rather than widen the gulf between them.

The coupling of this approach with semi-structured interviews regarding pressing contemporary issues proved crucial, as many important interrelations only revealed themselves after a certain time spent in the field. The fieldwork consisted of 4 weeks in March-April 2019, partly during rice harvest season, with 16 semi-structured qualitative interviews, and many informal conversations resulting from the researchers' participation in daily life in the village. Since LEK is a formalinformal hybrid and consolidated and shared collectively (Fazey et al. 2012; Bryceson and Ross 2019), particular attention was paid to having a wide spectrum of interviewees, covering all of the important aspects of the local village network and not only a narrow section of it. As Bundy and Davis (2012) point out, many studies on LEK prioritize primary producers, in particular farmers and marine or woodland harvesters, which only scratch the surface of the whole potential of LEK. Therefore, with our selection of interviewees, we go beyond the direct impact of the environmental crisis unfolding in the lagoon and include the indirectly affected members of the village network as well. Thus, there was a focus on three subject groups for the interviews: (1) "primary producers," such as fishermen, aquaculture operators (AOs), and farmers; (2) "service providers" which include mostly traders, members of the woman's union, and homemakers; and (3) "leaders" who are part of the formal institutional governance structure, for instance, holders of political roles. This 
procedure allowed for the subsequent comparison of the various emphases of different stakeholders and investigation of the adaptive methods used by the different subject groups.

\section{Case description}

The village of Trung Làng sits at the northern edge of the lagoon where the Cưa Lác dam separates brackish lagoon waters from fresh water coming from the tributary Ô Lau. The 2002 constructed dam functions as a salinity control measure, reduces flood risk, and is accessible as a shortcut between the commune and the coastal area. However, one AO explained that with the obstruction of seasonal currents, many migratory fish species disappeared, because past gradual changes in salinity and water levels now occur abruptly. The village of roughly seven hundred inhabitants features residential houses, one paved main road, one community center (Nhà Văn Hóa), several shops, mooring spaces at the lagoon shore, and a cafe with a beach volleyball court in the village center. Furthermore, speakers are spread around the village broadcasting news twice a day, focused on the distribution of tasks and any other necessary information. The cafe, as well as a few shaded places along the pier where the elderly meet, serves as the main place of intercommunal communication. It is the first place in the morning, where villagers gather to discuss fish prices, catch amounts, recent fish dying events, and occurrences of seagrass in the local environment. It is also where, in the afternoon, many spend their free time and gather to play games on their mobile phones, read, converse with one another, or engage in card games and gamble. The square in front of the Nhà Văn Hóa, cafe, as well as the road and private front yards, are repurposed as drying spaces for rice during harvest season, approximately two to three times a year. There is also a small shrine located near the lagoon shore, which sometimes featured small offerings; however, it was reported that it is not used often anymore, as the former custom of spiritually guided harvesting methods and periods has mostly vanished. Instead, farmers and AOs have to formally adhere to the timetable of harvesting machines that usually are leased by groups or the whole commune for a limited time period.

Traditionally there are two main groups in the community: farmers, mainly growing rice, peanuts, and a few other tuber vegetables, and fishermen, catching wild fish, operating aquaculture ponds, or both. The most common fishing methods for commercial use are Sáo, huge bamboo constructions build alongside the flow of the water current to trap larger fish at the end, and Lừ, a kind of bow net to catch smaller fish, crab, and shrimp. While recreational fishing became increasingly popular among younger generations, older traditional ways, such as Chuom, a bamboo fish trap lowered to the lagoon bed, have been vanishing quickly. Additionally, destructive fishing methods, such as electricity fishing and dragnets, which destroy the surrounding natural habitats, were very popular in the early 2000s but have been banned after natural fish stocks almost collapsed. However, many villagers complain about people still using these methods despite the risk of punishment.

The operation of aquaculture is by far one of the most timeconsuming jobs in the commune. It comprises a variety of tasks to be completed on a weekly basis, such as the harvest of seagrass as fish food for the ponds or the cutting and trimming of bamboo poles as a preparation for construction of new ponds in the coming season. Since fish theft happens occasionally, AOs sleep on the lagoon on small self-constructed platforms to protect their fishponds. The most common fish species raised in the ponds is the grass carp, whereas pangasius and mullet are mostly caught in the wild. Fresh fish is sold directly at the lagoon shore each morning at sunrise at the same place. There is no access by road; traders therefore have to arrive and depart by motorcycle over dirt paths. However, most traders are related to the fishermen, often live in the village as well, and bring the fish to the next local market. Larger quantities of fish, for instance, following a clearance of a fishpond, are oftentimes sold to outside middlemen and brought to the nearest city for further processing.

Regarding village internal issues, such as theft, spatial conflicts, or any kind of turmoil, the village head (Trưởng Thôn) is the main contact person. He is also responsible for advising people about flood preparation measures and monitoring the response. As he often takes over the role of a coordinator between various people with various functions, he has a good overview of current village internal developments and needs. Nonetheless, regarding external matters and formal exchange of information with higher administrative levels, the political leader of the commune, the Bí Thư is in charge. Both of them often had a clearer means to articulate themselves regarding village concerns than the other subjects interviewed, as they are working with these issues on a regular basis. Furthermore, various local socio-professional organizations, such as the Women's Union or fishing and farming associations, hold formal roles of rights allocation and information sharing. In particular, members of the Women's Union and trader groups have been observed taking on the role of an informal information organization, such as providing environment-friendly waste disposal, filing complaints and feedbacks, and passing on information from city traders.

\section{Experiences and perceptions about socio-ecological changes}

\section{Environmental dilemmas}

The rapid decline in water quality over the past 5 years is a major recurring theme in the interviews. Regarding impacts 
and consequences for community life, however, perceptions and experiences differ between the subjects of investigation. Fishermen and AOs of the first subject group were mostly concerned about the decline of natural seagrass beds in the lagoon, which need a habitat of healthy levels of water quality to survive. One AO, 59 years of age, explained: "When I started raising fish, there were seagrass beds right next to my cages, basically everywhere. Now they are all gone and we have to search for them." The seagrass not only serves as an important nursery environment for sheltering young wild fish but is also harvested as natural food for fish raised in the aquaculture enclosures. If the seagrass disappears, AOs have to resort to costly industrial fish food, which, according to both fishermen and traders, has the side effect of making the fish grow larger faster and change their taste and texture. AOs now have to search for the remaining seagrass beds and travel much farther distances and hence spend more money, gasoline, and time compared with earlier when seagrass beds were still plentiful. One younger AO mentioned: "There are times when they have no other choice than to use the industrial fish food, although they know its downsides." Furthermore, rapid decreases of water quality have already led to sudden fish dying events in the past, which left several AOs losing their harvest of the entire enclosures overnight. One AO observed that dying events especially happen throughout the months of August and September when wild fish species also die and come floating downstream the river Ô Lau. All interviewees from the primary producers suspected that the reason for the water quality decline originates from illegal activities by a factory upstream, but none of them could confirm that with certainty. One fisherman specifically mentioned the Formosa marine life disaster of 2016 as the reason for the general water quality decline. Another reason often cited for contributing to the deteriorating water conditions is the use of destructive fishing methods, which churn up the lagoon bed or intrude on and spoil other natural habitats. An older fisherman explained visibly concerned: "It's all because of those illegal activities. They are forbidden now, but people are still using them."

The onshore counterpart to the situation in the lagoon is the dilemma of rice farmers. To raise the levels of agricultural production, nearby forests have been cut down, slash and burn harvesting methods have been deployed, and pesticides and fertilizer are used extensively. This has caused problems with soil erosion and infertility. One farmer remembered that there used to be a brown-colored, fertile, thin surface layer on the ground, which now has given way to a white and infertile sand layer. Moreover, farmers mentioned detrimental impacts on their crops at times when they use lagoon water for irrigation and the longer dry periods make them rely on the water more frequently. In turn, members of the service providers mentioned that the intensive use of pesticides and fertilizer in farming further contributed to the water quality decline. One woman pointed out: "Farmers burn the left-over straw in harvest periods because they believe it would get rid of the diseases in the ground. "However, this may only be a secondary reason, according to the Trường Thôn, as the village does not hold cattle, which the straw could be used for otherwise. Moreover, he added: "Carting it off would also be too timeintensive and not worth the effort. "Most farmers interviewed were well aware of and unhappy about their dependency on the fertilizer, pesticides, and environmentally unsound harvesting methods. They mentioned however: "We either use pesticides and fertilizers or we cannot harvest" and "burning the grass is the most practical way to deal with it, we have no other option". In another village, Phú Xuân, further south along the lagoon, leftover grass is used to fill large planters for growing mushrooms. Apparently, this is not practical in Trung Làng, as the village is situated lower and frequent flooding events do not allow for such constructions.

Members of subject group 2, the service providers, are mostly indirectly impacted by the decrease in water quality. Their biggest concern is the "poisoning" effect it has on the fish and other food derived from the lagoon for local consumption. A shop owner and member of the Women's Union stated, "If the lagoon is not healthy, the fish are not healthy. That means the fishermen cannot sell their products, which in turn means they do not have enough money to come to my shop, and we do not have anything to eat."

They also put emphasis on another source of pollutionwaste. Lagoon waters, village pathways, backyards, rice fields, and especially the coastal areas around the lagoon are all subject to arbitrary disposal of garbage. In order to efficiently utilize organic waste, every household keeps at least one or two swine, which are fed all organic leftovers. While interviewees of the service providers picked this topic of conversation mostly by themselves, the primary producers only talked about it after it was specifically brought up during interviews. One AO explained that smaller plastic particles can negatively affect fish species, while bigger pieces of trash get stuck in propellers of motor boats in shallow water or obstruct plowing activities in the fields. The Bí Thư and Trưởng Thôn explained that the increased trash in the environment is due to higher consumption rates, increased availability and the variety of products in countryside stores, population growth, and different packaging methods compared with the past. In the past, food items, for instance, were stored in banana tree leaves and carried to and from markets in woven baskets. Nowadays, people use plastic for everything.

The abovementioned conditions have combined to make the fishing and aquaculture businesses a risky field of work. AOs have higher expenditures of time and money while having a less stable income. Traders further remarked that the combined factors of overexploitation (regarding catch amount, size, age, and rarity of species), seasonal changes, increased competition of traders, varying pollution effects, 
and even rumors about pollution events or affected species could trigger immense price variations on a daily basis. Furthermore, the interviewees from subject group 3, leaders, mentioned the new establishment of bigger export- and service-oriented companies, such as SCAVI or CP, which focus on mass production (e.g., shrimp) and are privileged by the government when it comes to land use rights. Lastly, climate change impacts, such as longer, unpredictable, and frequent flood and heat periods, were mentioned both by members of the primary producers and leaders as not only contributing reasons for the unstable job situation but also as impairments of safety bringing an increased pressure on farmers during harvest season.

\section{Government inertia in meeting the needs of the village}

Another recurring theme during interviews was the desire for more effective government intervention regarding complex multidimensional issues, such as water pollution, which is too great to handle for the average individual local resource user. Primary producers, in particular, wish for higher-level engagement, organization, and regulation. The decisionmaking power lies outside the commune and powerful corporate stakeholders like SCAVI or CP, with their share in responsibility for the water quality changes, are out of their reach. Thus, in the words of the Bí Thư, "there is nothing left for us to do than to alleviate the effects." This is in line with the statements made by scholars at the Hue University of Sciences, who made recommendations regarding the site selection of the research. Regarding local expertise, one staff member was concerned that "if researchers or responsible officers need something from here, they just go, get it, and leave again." Moreover, as for the long-term vision of the lagoon's management she added, "There is none. The commune is left alone with its challenges. Authorities only step in when they consider the case urgent enough. The impact of pollution is not sudden enough, and statistics will not have any effect."

Especially concerning the provision of information and other public services, interviewees complained about being left in the dark by the authorities about the real reasons for the water quality decrease and what actions should be taken to solve the issue. Consequently, the Bí Thư explained that his position is getting more responsibility and increased pressure, being the only formal connection between authorities and village. However, he also explained that the flow of information on environmental situations is practically non-existent as he is restricted to only report on social economy and security issues. Some people mentioned that there have been workshops over the past years, even including feedback sessions providing locals the opportunity at least to reach out to district level officials. However, those workshops took place outside the commune and the respondents noted that the events quickly turned out to serve only two purposes. First, one wanted to find out how well government-induced rearrangement measures have been adopted and, second, who is eligible to receive financial compensation.

\section{Village network adaptations and perceived government responsibility}

\section{Fishing and aquaculture in polluted waters}

Alongside the progressive loss of natural resources, less efficient fishing methods of the older generations, such as Chuôm fish trap, are also vanishing. In order to make up for the increasing lack of resources, the first reaction has been the intensification of all other extractive methods and aquaculture. The initial wave of what are now illegal destructive fishing methods has been repressed by government initiatives, but depending on who is asked, they are still occasionally or even frequently in use. One older fisherman stated that the problem with those methods is that one can catch more fish in the shortterm and thus make more money, at the cost of all other inhabitants of the village. However, he further noted "If you apply these methods you will always live in fear of punishment by the authorities." Generally, one can say that destructive fishing methods are socially frowned upon. People carrying the electric fishing equipment usually avoided eye contact with others in the village, and other people describe their catches as "not good quality" or "very cheap."

A larger and less manageable problem is the increased density of meshes of fishing nets, which are capable of catching younger and smaller fish, which would normally slip through and guarantee future catches of larger fish. However, lagoon resources have reached a point of depletion where locals feel forced to resort to the new nets. According to one AO, some have actually increased the size of and distance in-between net enclosures to improve water flow and quality. However, at the same time, others are acting the opposite way, to increase their output to make up for previous losses, and therefore contribute to the deteriorating water quality even further. Additionally, many AOs experiment with various fish species, observing which fish can survive best under the new, worsening conditions.

\section{Food anxiety in families}

Next to their awareness of water quality affecting the fish for daily consumption, the service providers also expressed high levels of mistrust in the industrial fish food and concerns about the overuse of chemicals in agriculture. The women interviewed said that they often walk very selectively through market aisles, deliberately only buying slow-growing, "low- 
value" vegetables, such as pumpkins, gourds, and zucchinis. Due to the low profitability of these vegetables, they know that farmers do not plant those extensively and thus avoid chemicals. Due to the impacts of industrial fish food on fish raised in aquaculture, locals now prefer wild fish, such as pangasius or mullet, despite the higher prices. Fish raised in aquaculture are cheaper and mostly sold to outsiders and city traders who do not know or care about the quality differences. After the Formosa marine life disaster, fish were entirely off the list for an extended period of time. People then relied mostly on their own poultry. The situation was further exacerbated after a wave of swine flu, which also made pork a taboo. Summing up the daily repeating food dilemma, one homemaker noted defenselessly: "You have to choose your food carefully when going to the market, but most of the time you do not have a choice anyway. If you do not eat you will die, but if you eat you will also die."

\section{Livelihood diversification and its consequences for the family and village}

One of the most common responses to the seemingly insoluble working conditions is the diversification of livelihood sources. There are notably three different forms of livelihood diversification in Trung Làng. The first one is the addition of new elements to the daily activities and re-distribution of tasks and activities among family members. Many women, for instance, instead of helping out with fishing activities in the lagoon, have now taken up fish trading to assist their families in selling the fish catches or aquaculture products to add to family income. Others have added a hair salon compartment to their houses, worked as drivers, or found an additional income source in collecting and reselling recyclable waste. The problem with this mixed diversification is that it clashes with the very timeconsuming and energy-intensive aquaculture and fisheries lifestyle. Therefore, many primary producers are in the midst of a transition of completely abandoning aquaculture and switching to providing new services, which is the second form of intercommunal livelihood diversification. This has led to a higher variety of services available in the area than before. According to the Trưởng Thôn, the most popular new jobs are clothing tailor and construction worker. Some fishermen and AOs decided to focus entirely on agriculture, which has slowly led to a constellation shift within the commune, from water-related activities being the majority to now terrestrial activities.

The third form of livelihood diversification manifests itself through generational adaptation. Since village life cannot be sustained entirely by living off the lagoon anymore, older generations do not see a future in the fishery business for their children. Most young people therefore leave for the bigger cities, such as Da Nang, Ho Chi Minh, or Hanoi, to study or earn a living and support their families with money transfers from a distance. An older woman noted, "Only long-time fishermen continue to go on, young people mostly do not even start at all. "It is too hard for young people to get a hold in the industry under the new conditions. Some are especially unlucky, as they had already bought all the necessary equipment but now desire to quit. Most of them either wait for more government compensation or work in one of the new aquaculture companies around the area. The Trưởng Thôn and the Bí Thu have in fact assessed this as a positive development, as it provides young people with the opportunity to receive a stable income and keeps the poverty level in the village low. In general, the fact that the new generation discontinues with the traditional lifestyle does not affect the older generations. On the contrary, they are rather happy and not worried about the future, since life quality has improved overall and most of their children have managed to make the transition.

\section{Climate change impacts and new developments}

In the face of changing weather conditions and increased frequency of flood events, villagers are encouraged by the authorities to build safer, two-story houses with solid roofs. Walking through the village, one can notice the many new developments taking place, providing opportunities for former AOs to find work in construction. However, there is a second reason for the manifold new developments - comfort. Some members of the service providers explained that solid roofs provide a cooler interior and are less noisy during rain than the earlier corrugated tin roofs. These roofs are also important for the household to enjoy and protect their newly purchased television sets. New houses often also include the acquisition of fans, fridges, water filtration systems, and bathrooms, which were all still uncommon 10 years ago, according to the Trưởng Thôn. These new developments allow for leisure activities, longer indoor working times, better storage of food, and increased independency from natural water reservoirs, which makes the impact of water pollution appear less grave. However, these developments also come with changing demands, such as a functioning water sewage system, which are still poorly managed. Most sewage flows into backyards to percolate into the ground. Furthermore, these new developments demand a high amount of space in the commune. Spatial conflicts between neighbors therefore occur more frequently. One woman lamented that many have to sacrifice their private vegetable garden for the sake of the new houses. Consequently, they now have to go outside to buy vegetables. However, she added that young people are not interested in vegetable farming anymore anyways and buying them outside the home is more convenient and time efficient. Also noteworthy are two huge contributing factors to making new developments within the village possible: firstly, the money available sent in by their sons and daughters working away 
from the village and, secondly, the residents nowadays have the option of paying larger sums of money in installments if necessary.

\section{Motivations for individuals and families to adapt}

There is a general feeling of powerlessness and lethargy among locals. Upon being asked whether people would like to help by sharing their knowledge, one $\mathrm{AO}$ answered, "Of course I am sharing my knowledge with anyone who asks, but nobody is asking." However, the most used phrase by locals was "let it be." Despite the many troubles and changes, people are positive about life generally being better than it used to be. One woman remarked, "All in all, life has gotten much better, but the environment is worse off. Therefore we cannot be fishermen anymore." This "let it be" mindset is particularly prominent among younger generations. However, older generations do not find this irritating. The same woman further added, "Young people may not care anymore, but life is changing. They change their jobs and that's just how it is. The only thing I am sad about is when they have to leave for the city." Similar remarks could also be made about the local knowledge and beliefs that are constructed spiritually. Only a few older inhabitants in the village remain knowledgeable about the former spiritual component of resource harvesting and they were not particularly open about it. Younger people mostly referred to older generations when asked about this issue and remarked that they only pray to ancestors that the future would be a good one.

While interests and discussions associated with traditional beliefs, social learning, and ecosystem vulnerability are rather low and neglected, interests associated with one's own survival, economic situation, and community welfare and well-being are predominant. People often assigned a monetary value to subject matters in the interviews and conversations without being asked about it, usually also annotated with the comment of being cheap and that everything of higher value (e.g., larger fish species) has disappeared. Moreover, primary producers were mostly preoccupied with livelihood concerns and harvest yields, while members of the service providers payed much more attention to raising one's own living standards. Members of the leaders group were the only ones mentioning any interest associated with resource governance.

\section{Discussion}

\section{Disregarding self-organized adaptations}

Many of the findings show a trend of limited and often tokenistic co-planning of resources in the lagoon community. Authorities only intervene in the most urgent matters, there is no apparent overarching long-term vision, and locals have no feasible opportunities in tune with their changing lifestyles to make an impactful contribution to the planning of the village. In addition, our research interest in them as individuals and in the daily life of their village, which involves staying for a rather extended amount of time in one place far from areas most visitors roam, came as a surprise to many actors involved. Therefore, the intra-communal solution communication process happens only on the village level, closed off from any outside interested party. Due to the leaping gap between local and district levels, planners miss out on this local discussion as well as any consequential self-organized network adaptations (Boonstra and Boelens 2011). These could provide valuable insights for improved local decision-making, problem-solving and communication between actors to avoid potential future maladaptation and misinterpretations by stakeholders (Berkes et al. 2000; Al-Roubaie 2010; Bundy and Davis 2012). This does not remain unnoticed by the local population. Not only do they feel kept in the dark regarding information on important happenings within the lagoon but also left alone when it comes to handling them. The overwhelmingly interconnected issue of water quality decrease and loss of their livelihood sources combined with this feeling of powerlessness and having no voice evoked in many a mindset of forlornness, or in the words of most locals: "let it be." Having abandoned many traditional livelihoods, there is little motivation left to fix the underlying cause of the problems but only to evade their consequences by becoming more independent from the degraded resource in the presence of ineffectual authorities.

This feeling of (economic) insecurity and uncertainty about how to handle the situation combined with growing distrust in experts and authorities are the underlying drivers for the resulting self-organized actions (Hornidge and Antweiler 2014). Actors of such self-organizational behaviors often tend to establish their own rules and practices and are able to coexist with or resist central guidance and regulation in order to strive for a desirable social-ecological setting or survive in an undesirable one (Rhodes 1996; Kooiman 2003; Fuchs 2006; Teisman et al. 2009; Boonstra and Boelens 2011). However, in this case, these self-organized actions do not manifest in increased political activities or collective social movements. People have learned that nothing will change, their voices will not be heard, and their time-consuming livelihood activities will not provide them the opportunity to spend extra time and energy to engage in the first place. Therefore, most locals do not join any community or political board; and the few who do cannot reach higher than the local level or have to adhere to restrictions in the provision of information. Instead, selforganized actions come in the form of new network adaptations, often resulting in newly emerging socio-spatial groups, services, functions, or sources of livelihood, such as hair salons, driving services, or construction.

The most common way out, for those who can afford it, is livelihood diversification. This process provides a form of 
local social and economic resilience in times of environmental instability and change (Nakashima 2012). The three types of livelihood diversification seen in the village are good examples of this process of detachment from lagoon resources. Nevertheless, one can find more kinds of self-organized village adaptations to the many issues discussed above, such as the informal organization of waste collection and recycling, the experimenting with different fish species, or the use of fishing nets with increased density of mesh. Some of these adaptations come with yet again further increase in pressure on lagoon resources, as demands and consumption rates are multiplying. Ecosystem services are often only barely functioning, provided at a level just enough to maintain an income and gain time to change to a new livelihood source. Older generations who have seen the better days of the lagoon describe this process as a form of trade-off. One stated, "Life is better now, while the environment gets worse and worse. There is nothing else one can do except letting our children take up another profession." Being aware of local attitudes can be crucial for a planner of the lagoon's resources to understand the background of resulting local-level (mal-)adaptations. Since planners usually are not resource users themselves, it is important for them to have access to informal information exchange places and processes, such as the cafe in the center of the village. Such places provide the platform for collective knowledge formation, introducing new ideas and attitudes and potentially incite bottom-up changes.

Furthermore, what becomes clearly visible is that in order to get a good understanding of local issues, their backgrounds, and context, one has to include not only the directly involved stakeholders but gain also an understanding of the interrelatedness of the village network. We identified and used three different subject groups for analysis; however, depending on the local context, these could be extended. It often occurred that the information provided by one group complemented the narrative of another. The most prominent example here is the issue of local food. While the primary producers could often provide an in-depth information on where the fish is coming from and how it is caught, they many times did not mention any change or problems in their daily diets. The service providers, often women working in the trading business, on the other hand described grave changes in the average food intake of their families. They are further down the chain of consequences than the primary producers are and therefore have a better overview of correlations. That is also one of the reasons why members of the service providers often appeared to be much more specific when talking about what exactly should be changed in order to improve their situation. On average, they also delegate less responsibility to the government and think of solutions themselves. This is also because many of them are part of the Women's Union, which serves as a place of information sharing and discussion and can afford to focus on clear and proactive ideas, while other organizations and individuals are preoccupied with dealing with impacts instead. However, the Women's Union is often still forced into a passive role regarding reaching outside the local level, since their concerns are mostly not considered urgent enough.

\section{Disregarding underlying interests and motivations}

The event of environmental crisis and increased economic pressures on the lagoon provides an entry window for market pervasion in the form of industrial fish food or fertilizer and pesticides, which in turn, despite short-term benefits, has a detrimental effect in the long term. Making use of these market-based solutions is the easiest form of adaptation and quickest remedy to accommodate the major interests. However, later on, locals often face a dilemma. Their quick remedy indeed solved one problem, but often could not address the cause of it, and instead created new problems. Traditionally, the spiritual component, or in other words environmental consciousness and constraints, once served as a form of guidance in times of despair or ensured that situations like these could be avoided in the first place (Reichel et al. 2012; Berkes 2017). Similar to the study of Ehlert (2014) about traditional weather lore in the Mekong delta, one could argue here that the former moral framework in the Tam Giang Lagoon could not hold out against the pervading economic pressures and "progressive" forms of extraction. However, it is also important to mention that establishing a close relationship with the elders and accessing the spiritually constituted component of LEK is inherently time-intensive. The available time frame of this case study did allow the further verification of this point.

LEK has been legitimately linked to adaptive management, resilience, and social learning enhancing capacities (Berkes et al. 2000; Berkes et al. 2003). However, critical scholars such as Harvey (1993) and Nadasdy (2007) have pointed out that LEK itself is biased as it is coevolving with contemporary developments and new circumstances in the environment which are themselves shaped by the very economic imperative causing the ecological crisis in the first place. These underlying processes that shape and reflect social-ecological system behavior can arguably be recognized in the case of Trung Làng Village.

Livelihood concerns, directly or indirectly led by external market forces, represent the strongest drive for adaptations, resulting in a local transition process away from the traditional ways of managing natural resources, as seen in various places across Southeast Asia (Santasombat 2011; Hornidge and Antweiler 2014). For many villagers, accepting this means to survive in the newly emerging characteristics of their own social-ecological system. This explains the use of small-mesh fishing nets, disinterest in continuation of traditional lagoon activities, and the distribution of aquaculture products for sale to outsiders instead of utilizing for local consumption. The co- 
planned rearrangement of activities to save the lagoon from overexploitation and to make it more productive again in fact stimulated this transition even further. Young people whose parents have been compensated to quit the aquaculture business have a hard time gaining a foothold in the business without parental support and now, due to lack of other options, prefer to leave for the bigger cities or wait for more financial support by the government to arrive.

Along with these newly emerging system characteristics, new experiences with higher living standards and convenience increasingly affect villager's motivations to adjust their lifestyles. It is a fast-moving process, which can adversely affect lagoon resources, but also opens up new possibilities to adapt to trans-regional challenges such as climate change or flood risk. However, yet again, one has to keep in mind that everything regarding LEK is interlinked. New developments bring flood safety on the one side, but on the other, they, for instance, entail the sacrifice of local vegetable gardens. They bring comfort but also evoke spatial conflicts and new demands such as expensive sewage systems. These developments force a disruption of the applicability of the villager's LEK. Older generations are compelled to disconnect from their former state of LEK, while young people grow up disconnected from the start. Consumeristic and materialistic values as part of the new state of LEK determine their lifestyles. This helps them to fit into an emerging system, where the traditional ways of solely living off the lagoon cannot be sustained anymore.

It is important for adaptive planners to acknowledge that LEK does what the concept always has been doing (as also seen in Boonstra and Hanh 2015; and Nguyen and Ross 2017). It is coevolving and adapting to modern societal and economic developments and changes in the environment, by discarding (e.g., old fishing methods, spiritual components, etc.) or introducing anything (e.g., plastic, fertilizer, destructive methods) that is necessary or beneficial for surviving and striving in the newly emerging characteristics of the system. This depicts the slow detachment process from its natural environment (Santasombat 2011). However, this does not suggest guaranteed adaptive and resilience enhancing capacities, which scientists and adaptive planners can harvest through standardized planning measures. Furthermore, this also does not imply a lack of capacity to keep up with changes in the social-ecological system. That would only be the case if one merely defines LEK by its ecological component, which indeed is often eroding due to processes outside the local context (Ross et al. 2011). If one reviews LEK in a certain context of not only significant environmental constraints, but also local and trans-regional social, economic, political, as well as formal and informal factors, one can discover a much higher degree of interconnectedness and adaptive capacity and that one vanishing aspect of life may have only been replaced by another. This has been captured through the use of the ethnographic approach and integrating the three different subject groups into the research agenda. However, planners accessing LEK need to consider the dilemma of it being a consequence of system developments and relations, which makes the use of it as an information source less generalizable. The adaptive capacities are intrinsic, but the results might not be the ones desired by a planner, without prior in-depth research on the local network. The abovementioned general mindset of forlornness, livelihood diversification out of economic necessity, or the loss of ecological or spiritual components are all signifiers of this dilemma.

\section{Conclusion}

In the process of reviewing LEK for potentially improving the sustainable planning of villages and the use of their resources in developing countries, it is important to recognize that the concept is not fixed in time and space but changes and adapts over time. In this case study, a broad and flexible, yet scientifically significant, ethnographic participant observer approach provided the means to understand local complex and tacit processes in a village in Vietnam, similar to the way holders of LEK came about to perhaps better understand these processes themselves. It demonstrates how local experience can lead to the discovery of a multitude of actors with different interests and adaptive behaviors, interfering in diverse and sometimes contradictory ways in the same environment. Thus, it can show to sometimes doubting officials and conventional planners that through participation and immersion, LEK indeed can provide a valuable source of science-based information, crucial for improved decision-making. Moreover, the results show that missing or deliberately disregarding these insights could further induce the emergence of new self-organized developments and long-term maladaptation. For instance, many village adaptations are often a response to the individual's perception of inert authorities and market pressures, as well as higher family living standards increasingly taking over local values and traditional motivations guiding behavior and choices for the future.

Despite its potentials, however, one should not use the concept of LEK lightly. LEK by itself should not be seen as a self-contained instrument only waiting to be integrated into a planning formula, in which $\mathrm{X}$ represents the information required to receive a planning result. Through this research, it becomes clearer that for this there are too many constantly changing variables. The wider development, economic and social processes beyond the village, as well as values and interests of households and the community greatly impact the local network and have to be taken into consideration for planning processes. LEK's context-dependent, dynamic, and adaptive characteristics mean, for officials and scientists alike, that they have to extend their focus beyond just the 
"environmental" aspect of LEK to include its social and economic components and refrain from analyzing it from a distant planning office. Receiving valuable LEK-derived information can only occur through an in-depth, comprehensive ethnographic, and collaborative research at the local level.

Acknowledgments We would like to express our deep gratitude to Dean Duong Van Hieu, Mai Ngoc Chau, Thai Nguyen, Dung and his family, Bach, Truc, Duc, Long, and Pei for their support, advice, and warmhearted welcome.

\section{Compliance with ethical standards}

Conflict of interest The authors declare that they have no conflict of interest.

Open Access This article is licensed under a Creative Commons Attribution 4.0 International License, which permits use, sharing, adaptation, distribution and reproduction in any medium or format, as long as you give appropriate credit to the original author(s) and the source, provide a link to the Creative Commons licence, and indicate if changes were made. The images or other third party material in this article are included in the article's Creative Commons licence, unless indicated otherwise in a credit line to the material. If material is not included in the article's Creative Commons licence and your intended use is not permitted by statutory regulation or exceeds the permitted use, you will need to obtain permission directly from the copyright holder. To view a copy of this licence, visit http://creativecommons.org/licenses/by/4.0/.

\section{References}

Abelshausen B, Vanwing T, Jacquet W (2015) Participatory integrated coastal zone management in Vietnam: theory versus practice case study: Thua Thien Hue province. J Mar Island Cult 4(1):42-53. https://doi.org/10.1016/j.imic.2015.06.004

Agrawal A (1995) Indigenous and scientific knowledge: some critical comments. Indigenous Knowl Dev Monit 3(3):1-8. https://doi.org/ 10.7454/ai.v0i55.3331

Al-Roubaie A (2010) Building indigenous knowledge capacity for development. World J Sci Technol 7(2):113-129. https://doi.org/10. 1108/20425945201000008

Benham C (2017) Aligning public participation with local environmental knowledge in complex marine social-ecological systems. Mar Policy 82:16-24. https://doi.org/10.1016/j.marpol.2017.04.003

Bennett N, Blythe J, Tyler S, Ban N (2015) Communities and change in the Anthropocene: understanding social-ecological vulnerability and planning adaptations to multiple interacting exposures. Reg Environ Chang 16(4):907-926. https://doi.org/10.1007/s10113015-0839-5

Berkes F (2017) Sacred ecology. Routledge, Abingdon

Berkes F, Colding J, Folke C (2000) Rediscovery of traditional ecological knowledge as adaptive management. Ecol Appl 10:1251-1262. https://doi.org/10.1890/1051-0761(2000)010[1251:ROTEKA]2.0. $\mathrm{CO} ; 2$

Berkes F, Colding J, Folke C (2003) Navigating social-ecological systems: building resilience for complexity and change. Cambridge University Press, Cambridge

Bohensky EL, Maru Y (2011) Indigenous knowledge, science, and resilience: what have we learned from a decade of international literature on "integration"? Ecol Soc 16(4). https://doi.org/10.5751/ES04342-160406

Boonstra B, Boelens L (2011) Self-organization in urban development: towards a new perspective on spatial planning. Urban Res Pract 4(2):99-122. https://doi.org/10.1080/17535069.2011.579767

Boonstra WJ, Hanh TTH (2015) Adaptation to climate change as socialecological trap: a case study of fishing and aquaculture in the Tam Giang Lagoon, Vietnam. Environ Dev Sustain 17(6):1527-1544. https://doi.org/10.5751/ES-04953-170320

Bryceson KP, Ross A (2019) Habitus of informality in small scale society agrifood chains-filling the knowledge gap using a socio-culturally focused value chain analysis tool. J Asia Pac Econ:1-26. https://doi. org/10.1080/13547860.2019.1670930

Bundy A, Davis A (2012) Knowing in context: an exploration of the interface of marine harvesters' local ecological knowledge with ecosystem approaches to management. Mar Policy 38:277-286. https:// doi.org/10.1016/j.marpol.2012.06.003

Ehlert J (2014) We observe the weather because we are farmers' - weather knowledge and meteorology in the Mekong Delta, Vietnam. In: Antweiler C (ed) Environmental Uncertainty and Local Knowledge. Transcript, Bielefeld

Fazey I, Evely AC, Reed MS, Stringer LC, Kruijsen J, et al (2012) Knowledge exchange: a review and research agenda for environmental management. Environ Conserv 40(1):19-36. https://doi. org/10.1017/S037689291200029X

Fuchs C (2006) The self-organization of social movements. Syst Pract Action Res 19(1):101. https://doi.org/10.1007/s11213-005-9006-0

Hammersley M, Atkinson P (2007) Ethnography: principles in practice, 3rd edn. Routledge, London

Harvey D (1993) The nature of the environment: the dialectics of social and environmental change. Social Regist 29:1-51

Hornidge A, Antweiler C (2014) The nexus of agency, knowledge, and environmental change in Southeast Asia. In: Antweiler C (ed) Environmental Uncertainty and Local Knowledge. Transcript, Bielefeld

Houde N (2007) The six faces of traditional ecological knowledge: challenges and opportunities for Canadian co-management arrangements. Ecol Soc 12(2). https://doi.org/10.5751/ES-02270-120234

Kooiman J (2003) Governing as governance. SAGE, Thousand Oaks

Mamun AA (2010) Understanding the value of local ecological knowledge and practices for habitat restoration in human-altered floodplain systems: a case from Bangladesh. Environ Manag 45(5): 922-938. https://doi.org/10.1007/s00267-010-9464-8

McGregor D (2014) Lessons for collaborative involving traditional knowledge and environmental governance in Ontario, Canada. AlterNative 10(4):340-353. https://doi.org/10.1177/ 117718011401000403

Nadasdy P (2007) Adaptive co-management and the gospel of resilience. In: Armitage D, Berkes F, Doubleday (eds) Adaptive co-management: collaboration, learning, and multi-level governance. UBC Press, Vancouver

Nakashima DJ (2012) Weathering uncertainty: traditional knowledge for climate change assessment and adaptation. UNESCO; UNU-IAS., Paris

Nguyen TH, Ross A (2017) Barriers and opportunities for the involvement of indigenous knowledge in water resources management in the Gam River Basin in North-East Vietnam. Water Altern 10(1)

Phuong LTH, Biesbroek G, Wals A (2018) Barriers and enablers to climate change adaptation in hierarchical governance systems: the case of Vietnam. J Environ Policy Plan 20(4):518-532. https://doi. org/10.1080/1523908X.2018.1447366

Rathwell KJ, Armitage D, Berkes F (2015) Bridging knowledge systems to enhance governance of environmental commons: a typology of settings. Int J Commons 9(2):851. https://doi.org/10.18352/ijc.584

Reichel C, Martens S, Harms A (2012) Conflicting frames of reference environmental changes in Coastal Indonesia. In: Antweiler C (ed) 
Environmental Uncertainty and Local Knowledge. Transcript Verlag, Bielefeld

Rhodes R (1996) The new governance: governing without government. Political Stud 44(4):652-667. https://doi.org/10.1111/j.1467-9248. 1996.tb01747.x

Ross A, Sherman KP, Snodgrass JG, Delcore HD, Sherman R (2011) Indigenous people and the collaborative stewardship of nature: knowledge binds and institutional conflicts. Left Coast Press, Walnut Creek

Santasombat Y (2011) The river of life: changing ecosystems of the Mekong Region. Mekong Press, Chiang Mai

Stevenson MG (2006) The possibility of difference: re-thinking co-management. Hum Organ 65(2):167-180. https://doi.org/10.17730/ humo.65.2.b2dm8thgb7wa4m53

Teisman G, van Buuren A, Gerrits L (2009) Managing complex governance systems - dynamics, self-organization and coevolution in public investments. Routledge, New York/London
Van Tuyen T (2006) Participatory local planning for resource governance in the Tam Giang lagoon, Vietnam. In: SR Tyler (eds) Communities, Livelihoods and Natural Resources. IDRC, Ottawa https://doi.org/ 10.3362/9781780440101.004

Van Tuyen T, Armitage D, Marschke M (2010) Livelihoods and comanagement in the Tam Giang lagoon, Vietnam. Ocean Coast Manag 53(7):327-335. https://doi.org/10.1016/j.ocecoaman.2010. 04.001

Whyte KP (2013) On the role of traditional ecological knowledge as a collaborative concept: a philosophical study. Ecol Process 2(1):7. https://doi.org/10.1186/2192-1709-2-7

Publisher's note Springer Nature remains neutral with regard to jurisdictional claims in published maps and institutional affiliations. 